\title{
Nonthyroidal illnesses syndrome in full-term newborns with sepsis
}

\begin{abstract}
Maria Helena Baptista Nunes da Silva', Maria Cristina Korbage de Araujo', Edna Maria de Albuquerque Diniz², Maria Esther Jurfest Rivero Ceccon', Werther Brunow de Carvalho²
\end{abstract}

\begin{abstract}
Objective: To assess hormonal changes in nonthyroidal illness syndrome (NTIS) in full-term newborns (NT) with sepsis. Materials and methods: We included 28 NT with sepsis divided into 2 groups according to the time of normalization of serum and clinical indicators of infection: group $A(A), 16 N T$ with improvement in up to 8 days; and group $B(B), 12$ NT improvement after 8 days. Among the 28 NT, 15 NT progressed to septic shock, with 5 NT group A and 10 NT in group B. NT were excluded when they showed severe sepsis and asphyxia, and congenital malformations, as well as those whose mothers had thyroid disease and IUGR. Results: 17 NT (60.7\%) presented NTIS. LowT3 was observed in NTIS in 10 NT $(58.8 \%)$, and low T4 and T3 in 5 NT (29.5\%), all of them with septic shock. Two NT showed mixed changes (11.7\%). After sepsis was cured, there was no hormonal change, except in 3 NT. Administration of dopamine, furosemide, and corticosteroids did not affect the results. Conclusions: This study indicates that nonthyroidal illness syndrome may be transiently present during sepsis in full-term newborns, especially in cases of prolonged sepsis. LowT3 can occur without changes in reverse T3 (different from adults), and lowT4 and T3 occur mainly in patients with septic shock. Arch Endocrinol Metab. 2015;59(6):528-34

Keywords

Full-term newborn; thyroidal hormone; sepsis; septic shock
\end{abstract}

\section{INTRODUCTION}

$\mathrm{N}$ onthyroidal illness syndrome (NTIS) is characterized by changes in serum levels of thyroidal hormones, without classical thyroidal disease (1-3). It has been described in systemic diseases, such as sepsis, affecting adult patients, with few studies on thyroid function in newborns (NB), mainly those that undergo large surgeries, stress, dopamine, furosemide and glucocorticoid use. In adults and children, four hormonal changes may be observed in NTIS: low T3, low T4 and T3, high T4, and mixed changes (1-8). In adults, T3 and reverse T3 changes were reported by Peeters and cols., as prognosis indicators: high levels of these hormones increases the chance of death (9). In fullterm $\mathrm{NB}$, soon after delivery, physiological high levels of TSH are observed. However, from the $5^{\text {th }}$ day of life on, serum levels become normal. In premature newborns, low T3 and T4 are observed with normal thyroid-stimulating hormone (TSH), a finding that is absence in full-term newborns (10).

Neonatal sepsis is a frequent disease that lead to a pro- and anti-inflammatory response in the organism, affecting several tissues and modifying enzyme actions.
Clinical symptoms and laboratory changes in neonatal sepsis may be observed for different periods and with variable severity (11). Little is known about nonthyroidal illness syndrome in newborns with sepsis.

The objective of this study was to assess the presence of hormonal changes in NTIS in full-term newborns (NT) with sepsis of short duration, prolonged sepsis, and in cases of septic shock.

\section{MATERIALS AND METHODS}

The study included NT older than five days (considering that this is the age when hormones reach normal levels) admitted to the Intensive Care Unit 2 of the Instituto da Criança at HC-FMUSP, an external center to where NT with clinical and/or surgical diseases are transferred from other neonatal centers. This study was approved by the Research Ethics Committee at HCFMUSP. Parents or guardians of the NB included in the study signed an informed consent form for the children to enter the study.

Twenty eight newborns with sepsis and septic shock (as defined by the international criteria of Goldstein and cols. 2005, that were maintained in the publication 
of the surviving sepsis campaign of Delinger and cols., 2012 ) associated with reactive $C$ protein greater than $10 \mathrm{mg} / \mathrm{dL}(10-14)$ were included in the study.

Exclusion criteria were newborns with sepsis and severe asphyxia, congenital malformations, large surgeries, and whose mothers had thyroidal disease with IUGR, which could cause changes in hormonal levels.

Duration of sepsis was classified as sepsis of short duration (Group A) by the presence of clinical and laboratory signs until the $8^{\text {th }}$ day of evolution and prolonged sepsis (Group B) when signs were observed beyond the $8^{\text {th }}$ day of evolution (13). Cure was considered when clinical and laboratory variable of sepsis were absent and reactive protein $\mathrm{C}$ was lower than $10 \mathrm{mg} / \mathrm{dL}(12,14,15)$. NTIS was determined with patients showed changes in thyroid hormone levels: low T3, low T3 and T4, high $\mathrm{T} 4$ and mixed changes $(2,3,9)$. One-mL Serum samples were collected by peripheral venipuncture that was carried out for other exams necessary for the care of newborn with sepsis.

Peripheral blood samples were collected between the first and the $4^{\text {th }}$ day of sepsis diagnosis in all newborns. For Group B patients, new samples were collected, one or more times, in the presence of clinical and laboratory signs of sepsis. New samples were collected in the cure phase.

Samples were centrifuge and serum was divided into two aliquots that were identified and stores in a freezer at $-20^{\circ} \mathrm{C}$ until analysis of $\mathrm{TSH}, \mathrm{T} 3, \mathrm{~T} 4$, free $\mathrm{T} 4$ and reverse $\mathrm{T} 3$ by radioimmunoassay.

Blood culture, full blood counts, and reactive $\mathrm{C}$ protein were determined for all newborns. Cultures of catheter blood, urine and cerebrospinal fluid were also carried out. Reactive $\mathrm{C}$ protein was determined by nephelometry, and was considered high if above $10 \mathrm{mg} / \mathrm{dL}$.

Aerobic, anaerobic and fungi cultures were carried out by Bactecpedsplus/f*, Bactecplus/f* and Mike F, respectively, from Becton Dickinson (USA), and were analyzed by the automatic Bactec 9240 system (16).

Results were submitted to statistical analyses: Fischer exact test, Mantel-Haenszel and medians were compared by the analysis of variance for unpaired samples and Gaussian distribution. This study project was enrolled in CONEP under number CA AE 0329.0.015.000-03.

\section{RESULTS}

From the 28 full-term newborns included in the study, 16 NT (57.1\%) were classified in group A (A) and
12 NT $(42 \%)$ in group B (B). Mean duration of the symptoms in A was 7 days, and in B was 17 days. Septic shock was observed in $15 \mathrm{NT}$ (53.5\%), from with 4 did not show NTIS, with 5 NT from group A (31.3\%) and $10(83.3 \%)$ in group $\mathrm{B}, \mathrm{p}<0.007$.

NTIS was found in 17 NT $(60.7 \%)$, with 7 NT $(43.7 \%)$ in $\mathrm{A}$ and $10 \mathrm{NT}(83.3 \%)$ in $\mathrm{B}, \mathrm{p}<0.0039$; in 11 NT (73.3\%) with septic shock, 6 NT (46.2\%) without septic shock, $\mathrm{p}<0.14$. Low T3 was found in 10 NT in the overall analysis (58.8\%) with 5 NT $(71.4 \%)$ in A and $5 \mathrm{NT}(50 \%)$ in $\mathrm{B}, \mathrm{p}<0.73$. Serum T3 levels in newborns of group $\mathrm{B}$, in the first week of evolution showed a median of $0.64 \pm 0.126 \mathrm{nmol} / \mathrm{L}$, significantly lower than the $0.86 \pm 0.12 \mathrm{nmol} / \mathrm{L}$ median of newborns of group A, p $<0.049$. Fungi were only found in $5 \mathrm{NT}$ that were in group B, and from these, $2 \mathrm{NT}$ had NTIS, $\mathrm{p}=0.31$.

All 28 NT survived and it was not possible to correlate hormone changes in NTIS of NT with sepsis and poor prognosis. The outcomes that lead to mortality as described in adults and older children were not found in the group of patients studied.

Table 1 showed clinical and laboratory variables of newborns according to the duration of sepsis when they entered the study.

Table 2 showed the medians and standard deviations of thyroid hormones and TSH according to sepsis evolution in NT with NTIS (low T3, low T4 and T3 and mixed changes).

Thyroidal profile that was observed in cases of sepsis without shock was $(n=13)$ : normal in 7 cases; low T3 in 5 cases; and mixed in one case.

Thyroidal profile observed in cases of sepsis with septic shock was $(\mathrm{n}=15)$ : normal in 4 cases; low T3 in 5 cases; low T4 and T3 in 5 cases, and mixed changes in one case.

An important feature in relation to thyroidal profile was found in low T4 and T3 only in cases of sepsis with presence of shock, $5 \mathrm{NT}$ in the overall analysis (29.5\%), with $1 \mathrm{NT}(14.3 \%)$ in A and $4 \mathrm{NT}(40 \%)$ in $\mathrm{B}, \mathrm{p}=0.27$, which is in agreement with the studies by Papanicolaou (3).

Mixed changes were found in only 2 NT (11.7\%), in $1 \mathrm{NT}(14.3 \%)$ from A and $\mathrm{l}$ NT $(10 \%)$ from $\mathrm{B}, \mathrm{p}<$ 0.75 .

Another important feature was that the low T3 profile was more prevalent in this study, without any relationship with sepsis duration. According to other studies that showed significantly lower levels in patients 
with prolonged sepsis, no matter the presence of shock, no elevation in reverse T3 was observed, as described for other age ranges, and no change in TSH was observed in any of the groups, either. In the analysis of these cases, low T3 was not related with poor prognosis, as observed in adult patients. In adults, the presence of low levels of this hormone means severe disease.

After patients were cured, serum levels of hormones returned to normal in $88 \%$ of the newborns of $\mathrm{A}$ and $90 \%$ of $\mathrm{B}, \mathrm{p}>0.05$.

Dopamine was used in $14(50 \%)$ newborns during sepsis, and NTIS was found in 11 of them, without significant differences between those that did not receive dopamine and presented NTIS ( $\mathrm{p}>0.05$ ).

Corticoids in pharmacological doses, when patients were extubated, was used during sepsis in $14(50 \%)$ newborns, with 8 of them showing NTIS, 5 NT with low T3. No significant statistical correlation was observed between the use of corticoids and NTIS ( $\mathrm{p}=$ 0.93 ), or corticoid and low T3 ( $\mathrm{p}=0.77)$. In the present study, a case in group B did not show NTIS in any phase of the sepsis, but presented low T3 in the cure phase after receiving dexamethasone when mechanical ventilation was removed.
Furosemide was used in pharmacological doses in $14(50 \%)$ of the newborns. However, there was no significant difference in the occurrence of NTIS, compared with patients that did not receive this drug $(\mathrm{p}=$ $0.24)$

\section{DISCUSSION}

This is a prospective cohort study of 28 full-term newborns with late sepsis that confirms the presence of nonthyroidal illness syndrome associated with neonatal sepsis and assesses the interference between sepsis duration and occurrence of shock in thyroidal hormone levels.

Newborns older than five days of age were analyzed to prevent interferences with physiological variations of these hormones during this stage of life.

NTIS was found in more than a half of the full-term newborns with neonatal sepsis, more frequent in the group with prolonged sepsis, no matter the presence of signs of shock $(\mathrm{p}=0.31)$. Thyroidal profile obeved in cases of sepsis without the occurrence of shock was (n $=13$ ): normal in 7 cases; low T3 in 5 cases; and mixed in one case. Thyroidal profile observed in cases of sepsis

Table 1. Clinical and laboratory variables in newborns according with sepsis duration at the moment they entered the study

\begin{tabular}{|c|c|c|c|c|c|c|c|}
\hline Data & Group & Median & Standard deviation & Mean & Standard error & Range & $\mathbf{P}$ \\
\hline \multirow[t]{2}{*}{ Weight grams } & $A$ & 3514 & 1062.7 & 3450 & 200.83 & $1740-6500$ & \\
\hline & B & 3303 & 935.7 & 3342 & 132.24 & $1740-6500$ & 0.16 \\
\hline \multirow[t]{2}{*}{ Age days } & A & 24.7 & 15.62 & 21.5 & 2.95 & $5-66$ & \\
\hline & B & 35.12 & 24.35 & 31 & 3.44 & $5-65$ & 0.13 \\
\hline \multirow[t]{2}{*}{ Temperature $>38.5^{\circ} \mathrm{C}$} & A & 38.7 & 0.34 & 38.5 & 0.13 & $38.5-39.3$ & \\
\hline & B & 38.6 & 0.32 & 38.5 & 0.18 & $38.5-39.4$ & 0.40 \\
\hline \multirow[t]{2}{*}{ Temperature $<36.0^{\circ} \mathrm{C}$} & $A$ & 35.5 & 0.17 & 35.5 & 0.08 & $35.3-35.8$ & \\
\hline & B & 35.6 & 0.20 & 35.7 & 0.09 & $35.4-35.8$ & 0.20 \\
\hline \multirow[t]{2}{*}{ Heart rate } & A & 186.5 & 7.42 & 186.0 & 1.20 & $184-190$ & \\
\hline & B & 191.6 & 7.08 & 190.5 & 3.70 & $182-203$ & 0.15 \\
\hline \multirow[t]{2}{*}{ Respiratory rate } & A & 66.9 & 14.1 & 65.0 & 3.32 & $43-90$ & \\
\hline & B & 66.3 & 13.1 & 69.0 & 4.58 & $44-88$ & 0.45 \\
\hline \multirow[t]{2}{*}{ Leukocytosis } & A & 25010 & 3808.7 & 22500 & 1956.2 & $21700-32100$ & \\
\hline & B & 25792 & 5313.7 & 25800 & 1458.0 & $20900-42490$ & 0.75 \\
\hline \multirow[t]{4}{*}{ Leukopenia } & A & 3485 & 1110.2 & 3485 & 785.0 & $2700-4270$ & \\
\hline & B & * & * & * & * & * & \\
\hline & A & 0.45 & 0.38 & 0.28 & 0.15 & $0.14-1.50$ & \\
\hline & B & 0.20 & 0.33 & 0.16 & 0.004 & $0.15-0.40$ & 0.20 \\
\hline \multirow[t]{2}{*}{ Reactive protein C } & $A$ & 74.2 & 83.83 & 38.40 & 25.0 & $12.60-260.20$ & \\
\hline & B & 108,4 & 70,89 & 57,70 & 27,0 & $13,20-261,10$ & 0.18 \\
\hline
\end{tabular}

${ }^{*}$ Absence of leukopenia. 
with septic shock was $(\mathrm{n}=15)$ : normal in 4 cases; low $\mathrm{T} 3$ in 5 cases; low T4 and T3 in 5 cases, and mixed in one case. Goldsmit and cols. found $69 \%$ changes in thyroidal hormones in full-term newborns in intensive care units, with the same NB diagnosis of our cases (17).

Low T3 was the most frequent change in this NTIS cases, with levels $40 \%$ lower than the normal range, significantly lower levels in patients with prolonged sepsis, no matter the occurrence of shock. the elevation of re- verse T3 was not observed, as described in other age groups (1,18-20). Chopra, in 1997, described lower levels of T3 in up to $40 \%$ normal levels (1). T3 in NT of our study was even lower in group B $(72 \%)$ than in group A and was kept like this a longer period, practically until NT were cured. However, after that, normal levels were observed.

Low levels of T3 have been interpreted as an adaptive response to stress in order to save energy, reduc-

Table 2. Median and standard deviation of thyroid hormones and TSH according to sepsis evolution in newborns with NTIS (low T3, low T4 and T3, and mixed change)

\begin{tabular}{|c|c|c|c|c|}
\hline \multirow{2}{*}{ Hormone variable } & \multicolumn{4}{|c|}{ Median \pm standard deviation } \\
\hline & Group A (1) & Group B (2) & Cure (3) & $\mathbf{P}$ \\
\hline \multicolumn{5}{|c|}{ Sepsis in newborns with low $\mathrm{T} 3$} \\
\hline T3 (nmol/L) & $0.86 \pm 0.12$ & $0.64 \pm 0.126$ & $2.59 \pm 0.32$ & $\begin{array}{l}1 \text { vs } 2:>0.05 \\
2 \text { vs } 3:<0.001 \\
1 \text { vs } 3:<0.001\end{array}$ \\
\hline $\mathrm{T} 4$ (nmol/L) & $140.1 \pm 37.3$ & $133.7 \pm 68.4$ & $160.81 \pm 31.78$ & $\begin{array}{l}1 \text { vs } 2:>0.05 \\
2 \text { vs } 3:>0.05 \\
1 \text { vs } 3:>0.05\end{array}$ \\
\hline Reverse T3 (ng/dL) & $144.34 \pm 66.9$ & $79.48 \pm 9.6$ & $119.12 \pm 48.1$ & $\begin{array}{l}1 \text { vs } 2:>0.05 \\
2 \text { vs } 3:>0.05 \\
1 \text { vs } 3:>0.05\end{array}$ \\
\hline TSH (mUl/L) & $0.043 \pm 0.04$ & $0.044 \pm 0.01$ & $0.042 \pm 0.04$ & $\begin{array}{l}1 \text { vs } 2:>0.05 \\
2 \text { vs } 3:>0.05 \\
1 \text { vs } 3:>0.05\end{array}$ \\
\hline \multicolumn{5}{|c|}{ Sepsis in newborns with low T4 and T3 } \\
\hline T4 (nmol/L) & $221.36 \pm 0.0$ & $70.2 \pm 6.4$ & $184.68 \pm 10.29$ & $\begin{array}{l}1 \text { vs } 2:>0.05 \\
2 \text { vs } 3:<0.001 \\
1 \text { vs } 3:<0.001\end{array}$ \\
\hline T3 (nmol/L) & $0.75 \pm 0.01$ & $0.64 \pm 0.14$ & $2.26 \pm 0.12$ & $\begin{array}{l}1 \text { vs } 2:>0.05 \\
2 \text { vs } 3:<0.001 \\
1 \text { vs } 3:<0.001\end{array}$ \\
\hline Reverse T3 (ng/dL) & $114.5 \pm 3.5$ & $80.46 \pm 2.9$ & $76.0 \pm 1.3$ & $\begin{array}{l}1 \text { vs } 2:>0.05 \\
2 \text { vs } 3:>0.05 \\
1 \text { vs } 3:<0.01\end{array}$ \\
\hline TSH (mUl/L) & $0.084 \pm 0.0$ & $0.03 \pm 0.13$ & $0.28 \pm 0.06$ & $\begin{array}{l}1 \text { vs } 2:>0.05 \\
2 \text { vs } 3:>0.05 \\
1 \text { vs } 3:>0.05\end{array}$ \\
\hline \multicolumn{5}{|c|}{ Sepsis in newborns with mixed change } \\
\hline $\mathrm{T} 4$ (nmol/L) & $103.5 \pm 0.01$ & $204.3 \pm 6.43$ & $130.21 \pm 7.72$ & $\begin{array}{l}1 \text { vs } 2:<0.01 \\
2 \text { vs } 3:>0.05 \\
1 \text { vs } 3:>0.05\end{array}$ \\
\hline T3 (nmo/L) & $2.04 \pm 0.0$ & $7.34 \pm 0.0$ & $2.20 \pm 0.69$ & $\begin{array}{l}1 \text { vs } 2:>0.05 \\
2 \text { vs } 3:>0.05 \\
1 \text { vs } 3:>0.05\end{array}$ \\
\hline Reverse T3 (ng/dL) & $76.5 \pm 0.0$ & $125.5 \pm 0.0$ & $61.0 \pm 0.0$ & ${ }^{*}$ Few cases \\
\hline TSH (mUl/L) & $0.56 \pm 0.0$ & $0.77 \pm 0.00$ & $0.43 \pm 0.04$ & $\begin{array}{l}1 \text { vs } 2:>0.05 \\
2 \text { vs } 3:>0.05 \\
1 \text { vs } 3:>0.05\end{array}$ \\
\hline
\end{tabular}

${ }^{*}$ Few cases to statistical analysis. 
ing the metabolic rate and protecting the body from hypercatabolism caused by sepsis $(6,9)$. It may be said that adaptive response may have been more intense in newborns of group B, leading to greater reduction in metabolic rates. This response may have collaborated with prolonging the disease (9). It is known that necrosis tumoral factor inhibit the activity of hepatic Dl desiodase, which is the enzyme that catalyzed T3 and has been implicated in the pathogenesis of low T3 (21).

Elevation of reverse $\mathrm{T} 3$ in the low $\mathrm{T} 3$ syndrome has been described in adults and children. However, in newborns, low levels of reverse T3 have been found (20). In the present study, reverse $\mathrm{T} 3 \mathrm{had}$ a similar behavior to that observed in adults and was increased in one case in group A, raising the mean values of serum levels in this group. When sepsis is found tougher with low T3, reverse $\mathrm{T} 3$ is produced in normal levels, and elevation is due to lower clearance caused by $\mathrm{Dl}$ inactivation in the tissues. it may be inferred from the results obtained in the present study, that $\mathrm{T} 4$ is not converted into reverse T3, the main pathway for the clearance of reverse T3, which may be little frequent in the neonatal period, at least in tissue level $(3,7)$. Low T3 has been described in other catabolic conditions besides sepsis, including fasting, decreased calorie ingestion, specially of carbohydrates, which decrease Dl activity and anticipate low T3 (3). In the present study, all the cases received adequate amounts of PPN with glucose, in spite of the fasting.

As the disease improved, T3 levels returned to normal, similar to other studies $(1,7)$. Low T4 and T3 were found in about $30 \%$ NTIS. This change, in some studies, was related with lower survival rates $(3,22)$. In the present study, this change similarly prevalent in both groups. However, it was observed only among newborns with septic shock. Den Brinker and cols. (23) found low T4 and T3 below in 50\% of the patients that survived septic shock by meningococcal disease, Yildizdas and cols. (18) found lower levels of T3 and T4 in children that underwent septic shocks than in children that did not. In the neonatal period, this change was observed by Franklin and O'Grady, who found four newborns with sepsis and changes in T4 and T3 that lasted until the $5^{\text {th }}$ day of the species. In these cases, T3 was persistently low until the $10^{\text {th }}$ day, when compared with healthy newborns $(24,25)$. These findings are similar to the ones of the present study, in a larger casuistry, though.

Serum levels of T3 and T4 in our study were significantly lower in NB with sepsis $(29.5 \%)$ when compared with NB that were already cured, without differences between group A (14.3\%) and B (40\%). Wilson and cols. also found in sick full-term newborns significantly lower levels of T4 in $66 \%$ of the cases, when compared with healthy full-term newborns (26). Some of the drugs used in severely affected patients may also change serum levels of thyroidal hormones and TSH. Among the most important drugs are dopamine, corticoids and furosemide, which were used in some newborns in the present study.

Dopamine in an adrenergic neurotransmitter that may inhibit TSH secretion by mean of adenylcytocyclase. This blockage may be due to the inhibition of the expression of the gene for the $\beta$ subunit of TSH that leads to the inhibition of the amplitude of nocturnal TSH peaks $(27,28)$. The inhibition of dopaminergic receptors, however, does not stimulate TSH $(27,28)$. When administered as an short-duration infusion of up to 48 hours, it may change TSH and does not seem to change T4, T3 and reverse T3 concentrations. When administered for more than 48 hours, besides reducing serum levels of TSH in up to $60 \%$, it may reduce T4 in up to $56 \%(29)$. The effect of dopamine was assessed in newborns of 12 to 90 days of life with congenital cardiovascular disease that showed increased TSH, without significant difference between continuous infusion or not $(30)$. In the present study $14(50 \%)$ of the newborns received dopamine, and NTIS was found in 11 of them. However, there was no significant difference between those that received dopamine presented NTIS $(\mathrm{p}=0.053)$. These results are similar to Den Brinker and cols., who also found an association between the use of dopamine and NTIS in children $(16,23)$. However, our casuistry is small, what may have influenced the final result, although our results are very close to the level of significance chosen in the beginning of the study. Besides, the neonatal period shows some peculiarities, several immature organs, and metabolic and neurological responses that are sometimes different from those found in older children, adolescents and adults.

Corticoids may alter serum T3 levels. Chopra and cols. observed that the use of dexamethasone may lead to reduction in T3 and elevation of reverse T3 12 hours after the beginning of the treatment (31). Gross and cols., in an experimental study, observed an increase in T3 in the fetus when the mother received betamethasone, but there was no change in T3 when the fetus received a direct injection of betamethasone (32). In the present study, the use of corticoid did not inter- 
fere in nonthyroidal illness syndrome, and 14 (50\%) of the newborns received corticoid in pharmacological doses when they were extubed. NTIS was observed in 8 of them, 5 with low T3. No significant difference was observed between the use of corticoid and NTIS $(\mathrm{p}=0.93)$, or with corticoid and low T3 ( $\mathrm{p}=0.77)$. One case in group B did not show NTIS in any phase of the sepsis, but presented low T3 in the cure phase after receiving dexamethasone when mechanical ventilation was removed, without any other explanation for this finding.

Furosemide binds strongly to tireoglobulin and produces a discreet dislocation of $\mathrm{T} 4$, increasing free T4 fraction $(27,32)$. In low concentrations, $3 \mu \mathrm{mol} / \mathrm{L}$, it does not show any effect on the hormones, but in high doses, of $30 \mu \mathrm{mol} / \mathrm{L}$, it increases free T4 $(33,34)$.

In this study, we concluded that low levels $\mathrm{T} 3$ in the first week of infection may indicate greater metabolic changes and prolonged infection. Although T3 showing lower levels in group B, this difference was not statistically significant when compared with group A.

The use of drugs such as dopamine and glucocorticoids did not influence TSH levels, once only 2 NT in 7 newborns with hormonal changes showed altered TSH and 5 NT with hormonal changes that were not treated with these drugs showed changes in TSH levels. The use of furosemide did not influence the occurrence of NTIS or TSH levels. NT that received only corticoid and did not show hormonal changes ( $3 \mathrm{NT}$ ) did not show changes in TSH, and from the NT that showed hormonal changes in this group, only one presented changes in TSH levels. Five NT showed sepsis without complications and did not receive vasoactive drugs and glucocorticoids. from these, 4 presented normal TSH and 1 showed altered TSH.

In conclusion, this study enables us to infer that nonthyroidal illness syndrome may be found transitorily during sepsis in full-term newborns, mainly in cases of prolonged sepsis. Low T3 may be observed without changes in reverse T3 in full-term newborns with sepsis and low T4 and T3 mainly in the presence of septic shock.

Individual contributions: Maria Cristina Korbage de Araujo was my mentor in this study, aiding in data collection, filling up of protocols and collection of samples from the newborns.

Edna Maria de Albuquerque Diniz, Maria Esther Jurfest Rivero Ceccon and Werther Brunow de Carvalho aided in the design of the study.
Acknowledgment: Mariza Kazue Umetsu Yoshikawa, for the support and aid in locating articles and in the review of the references.

Disclosure: no potential conflict of interest relevant to this article was reported.

\section{REFERENCES}

1. Economiedou F, Douka E, Tzanela M, Nanas S, Kotanidou A. Thyroid function during critical illness. Hormones (Athens). 2011;10(2):117-24.

2. Papi G, Corsello SM, Pontecorvi A. Clinical concepts on thyroid emergencies. Front Endocrinol (Lausanne). 2014;5:102.

3. Papanicolaou DA. Euthyroid sick syndrome and the role of cytokines. Rev Endocr Metab Disord. 2000;1(1-2):43-8.

4. Marks SD. Nonthyroidal illness syndrome in children Endocrine. 2009;36(3):355-67.

5. Chopra IJ, Hershman JM, Pardridge WM, Nicoloff, JT. Uncla Conference. Thyroid function in nonthyroidal illnesses. Ann Intern Med. 1983;98(6):946-57.

6. Stockigt JR. Guidelines for diagnosis and monitoring of thyroid disease: nonthyroidal illness. Clin Chem. 1996;42(1):188-92.

7. Langton JE, Brent GA. Nonthyroidal illness syndrome: evaluation of thyroid function in sick patients. Endocrinol Metab Clin North Am. 2002;31(1):159-72.

8. Golombek SG. Nonthyroidal illness syndrome and euthyroid sick syndrome in intensive care patients. Semin Perinatol. 2008;32(6):413-8.

9. Peeters RP, Wouters PJ, van Toor $H$, Kaptein E, Visser TJ, Van den Berghe G. Serum 3,3', ' 'triiodothyronine (rT3) and 3,5,3'-triiodothyronine/rT3 are prognostic markers in critically ill patients and are associated with postmortem tissue deiodinase activities. J Clin Endocrinol Metab. 2005;90(8):4559-65.

10. Dilli $D$, Dilmen $S$. The role of interleukin- 6 and $C$-reactive protein in non-thyroidal illness in premature infants followed in neonatal intensive care unit. J Clin Res Pediatr Endocrinol. 2012;4(2):66-71.

11. Goldstein B, Giroir B, Randolph A; International Consensus Conference on Pediatric Sepsis. International pediatric sepsis consensus conference: definitions for sepsis and organ dysfunction in pediatrics. Pediatr Crit Care Med. 2005;6(1):2-8.

12. Delinger PR, Levy MM, Rhodes A, Annane D, Gerlach H, Opal SM, et al. Campanha de sobrevivência à sepse: diretrizes internacionais para tratamento de sepse grave e choque séptico. Crit Care Med. 2013;41:580-637.

13. Ehl S, Gering B, Bartmann P, Högel J, Pohlandt FC. C-reactive protein is a useful marker for guiding duration of antibiotic therapy in suspected neonatal bacterial infection. Pediatrics. 1997 Feb;99(2):216-21.

14. Lacour AG, Gervaix A, Zamora SA, Vadas L, Lombard PR, Dayer JM, et al. Procalcitonin, IL-6, IL-8, IL-1 receptor antagonist and Creactive protein as identificators of serious bacterial infections in children with fever without localising signs. Eur J Pediatr. 2001;160(2):95-100.

15. Squire EN, Reich HM, Merenstein GB, Favara BE, Todd JK. Criteria for the discontinuation of antibiotic therapy during presumptive treatment of suspected neonatal infection. Pediatr Infect Dis. 1982;1(2):85-90.

16. Reisner BS, Woods GL. Times to detection of bacteria and yeasts in BACTEC 9240 blood culture bottles. J Clin Microbiol. 1999;37(6):2024-6.

17. Goldsmit GS, Valdes M, Herzovich V, Rodriguez S, Chaler E, GolombeK SG, et al. Evaluation and clinical application of chan- 
ges in thyroid hormone and TSH levels in critically ill full-term newborns. J Perinat Med. 2011;39(1):59-64.

18. Yildizdas D, Önenli-Mungan N, Yapicioglu H, Topaloglu A K, Sterdemir Y, Yüksel B. Thyroid hormone levels and their relationship to survival in children with bacterial sepsis and septic shock. J Pediatr Endocrinol Metab. 2004;17(10):1435-42.

19. den Brinker M, Joosten KF, Visser TJ, Hop WC, de Rijke YB, Hazelzet JA, et al. Euthyroid sick syndrome in meningogoccal sepsis: the impact of peripheral thyroid hormone metabolism and binding proteins. J Clin Endocrinol Metab. 2005 Oct;90(10):5613-20.

20. Hults JM, Goudoever JB, Visser TJ, Tibboel D, Joosten FM. Hormone levels in children during the first week of ICU-admission: is there an effect of adequate feeding? Clin Nutr. 2006;25(1):154-62.

21. Nagaya T, Fujieda M, Otsuka G, Yang JP, Okamoto T, Seo H. A potential role of activated NF-к $B$ in the pathogenesis of euthyroid sick syndrome. J Clin Invest. 2000;106(3):393-402.

22. Das BK, Agarwal P, Agarwal JK, Mishra OP. Serum cortisol and thyroid hormone levels in neonates with sepsis. Indian J Pediatr. 2002;69(8):663-5.

23. Den Brinker M, Dumas B, VisserTJ, Hop WCJ, Hazelzet JA, Festen DAM, et al. Thyroid function and outcome Intensive Care Med. 2005;31(7):970-6.

24. Franklin R, O'Grady C. Neonatal thyroid function: effects of nonthyroidal illness. J Pediatr. 1985;107:599-602.

25. Franklin R, O'Grady C, Carpenter L. Neonatal thyroid function: comparison between breast-fed and bottle-fed infants. J Pediatr. 1985;106:124-6.
26. Wilson DM, Hopper AO, McDougall IR, Bayer MF, Hintz RL, Stevenson $D K$, et al. Serum free thyroxine values in term, premature, and sick infants. J Pediatr. 1982;101(1):113-7.

27. Graf $H$, Carvalho GA. Fatores interferentes na interpretação de dosagens laboratoriais no diagnóstico de hiper e hipotireoidismo. Arq Bras Endocrinol Metab. 2002;46:51-64.

28. Moura EG, Moura CCP. Regulação da síntese e secreção de tireotrofina. Arq Bras Endocrinol Metab. 2004;48(1):40-52.

29. Kaptein EM, Spencer CA, Kamiel MB, Nicoloff JT. Prolonged dopamine administration and thyroid hormone economy in normal and critically ill subjects. J Clin Endocrinol Metab. 1980;51(2):387-93.

30. Van Den Berghe G, De Zegher, Lauwers P. Dopamine suppresses pituitary function in infants and children. Critic Care Med. 1994;22:1747-53.

31. Chopra IJ, Wiliams DE, Orgiazzi J, Solomon DH. Opposite effects of dexamethasone on serum concentrations of 3,3',5'-triiodothyronine (reverseT3) and 3,3'5-triiodothyronine (T3). J Clin Endocrinol Metab. 1975;41(5):911-20.

32. Gross I, Dynia DW, Wilson CM, Ingleson LD, Gewolb IH, Rooney SA. Glucocorticoid-thyroid hormone interactions in fetal rat lung. Pediatr Res. 1984;18(2):191-6.

33. Munro SL, Lim CF, Hall JG, Barlow JW, Craik DJ, Topliss DJ, Stockigt JR. Drug competition for thyroxine binding to transthyretin (prealbumin): comparison with effects on thyroxine-binding globulin. J Clin Endocrinol Metab. 1989;68(6):1141-7.

34. Lim CF, Bai Y, Topliss DJ, Barlow JW, Stockigt JR. Drug and fatty acid effects on serum thyroid hormone binding. J Clin Endocrinol Metab. 1988;67(4):682-8. 